
\title{
25 Research Square \\ Predation Risk is a Function of Seasonality Rather than Habitat Complexity in a Tropical Semi-arid Forest
}

Anthony Ferreira ( $\sim$ anthonyyferreira@gmail.com )

National Institute of Amazonian Research

Renato Faria

Universidade Federal de Sergipe

\section{Research Article}

Keywords: Predator-prey dynamic, natural structuring of communities, predation risk, animals living in different habitats

Posted Date: June 22nd, 2021

DOI: https://doi.org/10.21203/rs.3.rs-625459/v1

License: (c) (i) This work is licensed under a Creative Commons Attribution 4.0 International License.

Read Full License

Version of Record: A version of this preprint was published at Scientific Reports on August 17th, 2021. See the published version at https://doi.org/10.1038/s41598-021-96216-8. 


\section{Abstract}

Predator-prey dynamic is one of the most important species' interactions in the natural structuring of communities, and is among the more complex ecological processes studied by ecologists. We measure predation risk using artificial lizard replicas to test two competing hypotheses regarding predation pressure in semi-arid environments: (1) predation risk is dependent on the habitat structural complexity; and (2) predation risk is dependent on seasonality. We placed 960 replicas along three sites with different physical structures and in both seasons for seven consecutive days in a caatinga area in northeastern Brazil. Birds were responsible for the majority of attacks and more frequently on artificial lizards placed in trees. Attacks focused on the most vulnerable areas of the body (head and torso), proving that were perceived by predators as true prey items. We found that predation risk is not dependent on the habitat structural complexity, but rather dependent on the caatinga seasonality, with the overall attack being $19 \%$ higher in the dry season. Our study suggests that potential predation risk is highly context-dependent and that seasonality consistently drives of trophic interactions strength in the caatinga, an important ecological finding that could contribute to better understanding the complex evolution of predator-prey interactions within communities of animals living in different habitats.

\section{Introduction}

Predation is one of the most important processes in the functioning of ecosystems, with predators acting as key regulators of prey populations ${ }^{1-3}$. This selective pressure can determine demographic parameters, geographic distribution, population structure, evolution of morphological characters, life history traits and behavioral strategies, of both prey and predators alike ${ }^{4-7}$. The impact of predation on prey populations is best estimated using attack rates ${ }^{8-10}$, but these are notoriously difficult to measure in natural systems because of the rarity of observing predation events and fast consumption or removal of prey carcasses by predators ${ }^{2,11,12}$. Alternatively, an approach used in evolutionary, ecological and ethological studies consists of recording predatory attacks on soft replicas to quantify such events in nature, allowing the comparison of predation rates observed in different environments under different conditions ${ }^{13-15,12}$.

This technique is particularly useful since it allows identification of potential predators via examination of imprints on the replica surface ${ }^{16-19}$, being useful to test different ecological hypothesis in field experiments (e.g., ${ }^{20-22}$ ). The use of this simple and inexpensive technique has provided accurate and reliable estimates of potential predation risk, with highly illuminating results in studies involving bird nests $^{23,24}$, lizards ${ }^{2,11,25-29}$, amphibians ${ }^{15,19,30-32}$, snakes ${ }^{33-35}$, and also small mammals ${ }^{14}$.

Multiple factors can affect predation risk, including the habitat structural complexity and seasonality. Concerning predation avoidance, prey often respond to predation risk by increasing refuge use ${ }^{19,25,36,37}$. There is also large consensus that habitats with high structural complexity are expected to offer a large diversity of microhabitats that can be used as refuges and used by prey organisms such as lizards for cryptic concealment, thereby reducing predator foraging impacts ${ }^{11,38-40}$. Further, caatinga vegetation 
changes dramatically over the year due to its very marked seasonality and hence is expected to have important biological and ecological consequences such as predation pressure. Consequently, animals should adjust their refuge use in ways that reflect the increased predation risk $37,41,42$. If the extent of predation risk is not measured taking into account seasonal variations, especially in environments strongly marked by them, such as caatinga biome, it is not possible to distinguish which of these factors is more important in driving predation risk. However, the role of predation avoidance in the process of refuge use with habitat structural complexity as a function of seasonality in the caatinga biome remains unstudied.

To better understand this issue, we used attack rates on soft replicas as surrogates for lizards to directly quantify predation risk and examine the relative role of habitat structural complexity and inter-seasonality variation in determining predation risk. The primary goal was to empirically test two hypotheses regarding predation risk: (1) is predation risk dependent on the habitat structural complexity, i.e., does predation risk increase in less complex habitats; or (2) is predation risk dependent on seasonality, i.e., does predation risk increase in the dry season due the seasonally deciduous nature of caatinga vegetation that results in a loss of protective cover for potential prey? We further investigated predator attack patterns with respect to potential predators and the location of attacks on a lizard's body. Here, we provide empirical evidence that predation by visual predators such as birds is strongly modulated by local abiotic conditions in a lizard's community in a poorly-studied Brazilian biome highly threatened by anthropic actions.

\section{Results}

Environmental structure. The environmental variables measured for each site over 18 consecutive months are given in Table 1. The experimental sites differed considerably in relation to environmental variables (Table 1; Fig. 1). Tree, number of stems, rocks and bromeliads were higher at S2. Tree diameter, leaf litter and fallen trunks were higher at S1. Vegetation was especially sparse and low at S3.

The first axis (PC1) of the PCA for general structure explained $36.3 \%$ of the variation in the environmental variables data, whereas PC2 explained $28 \%$. The first axis (PC1) of the PCA for dry season summarized $39.5 \%$, whereas PC2 summarized $28.5 \%$. The first axis (PC1) of the rainy season PCA explained $39.5 \%$, whereas PC2 explained $28 \%$. The values for PC1 and PC2 were similar among the three PCA analyses, however, the environmental variables related to the variation of these axes were different.

The PC1 was related to the greatest number of stems and rock for general structure and dry season, while for the rainy season this involved the greatest number of stems and number of fallen trunks. Also, the PC1 was inversely related to the distance to nearest tree and nearest tree DBH for general structure and rainy season, and to the distance to nearest tree and proportion of exposed soil for dry season. The PC2 was related to the higher proportion of exposed soil and number of fallen trunks for general structure, DBH of the nearest tree, and leaf litter for dry season, and to the greatest number of rock and bromeliads for rainy season. The PC2 were inversely related to the higher proportion of leaf litter and DBH of the 
nearest tree for general structure, to the greatest number of fallen trunks and exposed soil for dry season, and to the higher proportion of exposed soil and number of stems for rainy season (See Supplementary Tables S1, S2 and S3 for values of all axes).

Differences in the environmental structure among the three experimental sites were observed for all 18 months (Pillai trace $=0.912, d f=102, P<0.001$ ), in the dry season (Pillai trace $=0.952, d f=54, P<0.001$ ) and in the rainy season (Pillai trace $=0.936, d f=42, P<0.001$ ). The measured environmental variables did not overlap (except for a slight overlap of the S1 and S2 in the general structure and in dry season) in multivariate environmental space (Fig. 1a, b, c).

Predation assessment. Nine hundred and forty out of 960 (98\%) lizard replicas were recovered from the experimental sites, of which 130 (14\%) showed some sign of predation (Supplementary Table S4). Six replicas were lost in the rainy season and 14 in the dry season. There was no significant difference in attack rate between experimental sites (intercept $\pm S E=-2.11 \pm 0.56$, Wald test, $P=0.07$; experimental sites (S1) $\pm \mathrm{SE}=-0.22 \pm 0.25$, Wald test, $P=0.37$; (S3) $\pm \mathrm{SE}=-0.07 \pm 0.24$, Wald test, $P=0.78$ ), with an attack rate of $4.6 \%$ at $\mathrm{S1}, 4.9 \%$ at $\mathrm{S} 2$ and $4.1 \%$ at S3 (Supplementary Table S4). However, was observed a significant effect of seasonality on attack rates (intercept $\pm \mathrm{SE}=-1.45 \pm 0.11$, Wald test, $P<0.001$; season $\pm \mathrm{SE}=-1.52 \pm 0.24$, Wald test, $P<0.001$ ), with replicas in the rainy season experienced an attack rate of 0.08 , while the predation rate in the dry season was about three times greater (odds ratio $=0.19$ ). In the rainy season, the highest predation frequency occurred in the most vegetationally-structured site (S2 with $4 \%$ ) followed by sites S1 and S3, with 3\% and 1\%, respectively. While during the dry season the highest frequency was in the less structured site, however moister due to proximity to a large river (S3 with 7\%), followed by sites S1 and S2, both with 6\% (Supplementary Table S4).

The use of microhabitats varied among experimental sites depending on their local availability, with $66 \%$ placed on the soil, $24 \%$ on rocks, and $10 \%$ on trees. Although with fewer placed replicas, the trees showed a higher predation rate with $47 \%$ attacks, followed by soil and rock with $11 \%$ and $6 \%$, respectively (Supplementary Table S4). The attacks on 94, 14, 4 and 3 models could be attributed to birds, ants, lizards and mammals, respectively, while the predators responsible for the attacks on 15 models remained unidentified (Fig. 2). Our attack rates on replica lizards likely represent a conservative estimate because all replicas that were attacked by predator classes of under-five attacks (lizards and mammals; $n=4$ and 3 , respectively), giant ant attacks $(n=14)$, or were missing upon collection $(n=20)$ were removed from analysis because we established a cut-off value below five, ants are not usually considered as lizard predators and the fate of the absent replicas could not be determined. Therefore, we only considered the attacks of birds, which were responsible for a majority of overall replica lizard attacks (72\%).

The body regions of the replicas were attacked similarly in the three experimental sites $(\chi 2=2.08, d f=4$, $P=0.72)$. However, the attack position on lizard's body differed significantly in the number of attacks in comparison to expectation ( $\chi 2=234.93, d f=2, P<0.001$ ), proving that the predators attacked the models non-randomly. In particular, the head was attacked significantly more (114 attacks; $59 \%)$ than expected 
by chance $(225.04$ expected attacks; $\chi 2=36.367, d f=1, P<0.001)$. The torso received $34 \%$ attacks and lastly tail with $7 \%$. There were no records of replicas with attacks on limbs.

\section{Discussion}

Our results showed that predation risk on lizards was not directly related to structural differences between habitats, suggesting that they were perceived as a continuous habitat, at least by birds, which were the main predators, therefore, lending no support to the hypothesis that habitat structural complexity drives predation risk. Instead, we found a significant relationship between seasons and predation risk, with a noticeable higher predation rates during the dry season, lending strong support to the alternative seasonality hypothesis. Our study constitutes one of the few empirical studies that identifies potential mechanisms underlying predation risk in a semi-arid environment, where predation rates were more influenced by local abiotic conditions, providing more evidence to compose the scenario of mixed results between different regions, as suggested by some studies (e.g., ${ }^{10,21,43-45}$ ). In addition, birds selectively attacked the replicas' head and more often on replicas placed in trees than on the most available microhabitats with them (soil and rock), indicating that they perceived lizard replicas as real prey items and were aimed to attack the most vital body region of their target organism in its main foraging microhabitat. This outcome was expected based on behavior of predators observed in other studies $^{14,18,19,22,46-48}$.

The climate and vegetation of the caatinga are very heterogeneous, which may respond for marked differences in local biological communities ${ }^{49,50}$. We observed a non-significant trend of increase in the observed number of attack at the less-structurally complex site (S3) during the dry season, but this site is located near the banks of the San Francisco River (which makes it the wettest site during this season). In the dry season, caatinga vegetation loses its leaves, becoming completely xeric, which drastically reduces humidity and overall resources availability (e.g., refuge and food items). Under such circumstances, animals seek more humid environments, regardless of their structural complexity which is generally associated with higher predation pressure ${ }^{39,51,52}$. Similarly, other studies have found a strong seasonal shift in the attack rates on lizards, with greater attacks frequency during the dry season ${ }^{21,53}$.

In contrast, the vegetation flourishes in the rainy season, increasing the availability of resources ${ }^{54,55}$, and more structurally-complex environments become more attractive for prey like lizards ${ }^{39,56-58}$. We also detected a non-significant trend of increase in the observed number of attack at the more structurally complex and denser sites (S2) during the rainy season. Castilla \& Labra (1998) found a negative, marginally significant rank correlation between predation rates on replicas with lizard density in both seasons, indicating that lizards tended to be more abundant in areas with lower on-replica predation intensities. Some studies have reported increased predation risk for lizards related to the abundance and diversity of predator ${ }^{39}$, lizard density ${ }^{59}$, and the abundance of alternative prey ${ }^{21}$. However, the increase in these factors does not necessarily mean they will contribute to increased predation (see $\left.{ }^{21,60,61}\right)$. Regrettably, in our study, the relationship between predator abundance and density, levels of food 
availability (alternative prey) and lizard density with predation risk were not investigated. Further research is needed to accurately examine the contribution of these factors to the predation risk, especially in this type of environment where food availability fluctuates seasonally.

A variety of animal species are considered as lizard predators, and predation of static replicas is attributed, mainly, to visually-oriented predators that forage actively ${ }^{11,62}$. In the current study, predatory birds were responsible for a majority of attacks on artificial lizards (72\%), a fact which fits with the classification of birds as the main predator of small herpetofauna in many ecosystems $\left(\mathrm{see}^{2,11,26,53,63-65}\right)$. Birds are excellent and voracious predators, precisely because their high metabolic rates result in high food demands ${ }^{7}$. Their excellent visual acuity allows them to perceive and attack prey even when immobile ${ }^{66}$. We suspect that majority of the bird attacks on artificial lizards came from diurnal predatory birds abundant at our sites. Ruiz-Esparza et al. (2011) ${ }^{67}$ carried out a daytime and nighttime inventory of the avian fauna of the Grota do Angico Natural Monument (GAMN) and revealed the presence of at least 140 species, where majority of the predatory birds are diurnal or crepuscular and forage on trees or near the ground. This trend was similar to other semi-arid scrublands across Brazilian northeast (e.g., $\left.{ }^{6-70}\right)$. However, we did not distinguish between daytime and nighttime attacks. A study that did this found no significant difference in the attack rates on artificial lizards from birds during the day or night ${ }^{21}$. They found that diurnal birds were the main contributors to the predation, especially at dawn and dusk, when many birds were foraging and lizards thermoregulating.

Although it is generally assumed that ants are not considered frequent predators of lizards, we found an interesting frequency of replicas attacked by the giant ant Dinoponera quadriceps ( $11 \%$ of incidents). Despite the potential impact of carnivorous ants on lizard populations, data on the actual intensity of predation is rare and fragmentary, often based on anecdotal and casual observations (e.g., ${ }^{71-73}$ ). Furthermore, it is probable that predation events by invertebrates on vertebrate assemblages are more frequent in nature than has been documented ${ }^{74-77}$, and large predatory invertebrates may be important predators of small lizards, even though invertebrates are often overlooked in this capacity ${ }^{78}$. Therefore, the assumption that carnivorous ants do not prey vertebrates with significant frequency, especially smaller or juvenile lizards should be validated on a case by case basis. However, due to skepticism surrounding this type of predation, we exclude ants from data analysis, but we warn that exclusions like this may produce spurious results. For example, it may inflate the relative frequency of other predatory animals or reduce the overall predation rate (see a similar case for attacks on artificial lizards from invertebrate predators - huntsman spiders and centipedes ${ }^{21}$ and daytime and nighttime predation by mammals ${ }^{22}$ ). The exclusion of attacks by the giant ant, in our case, did not change the overall pattern of results (see results with ants in Supplementary Table S5).

The use of artificial replicas is very advantageous because it allows testing rare events that are difficult to observe in nature or expensive to perform in the lab with experimental animal ${ }^{12}$. In addition, it allows researchers to display a large number of these replicas in the field, usually in a simple and inexpensive way, permitting a high statistical power to test several ecological hypotheses in field experiments ${ }^{14}$. 
However, this technique has obvious and important drawbacks: the absence of motion and typical prey odours, spectral colour differences in comparison to the living animals and usually are displayed continuous in the field without distinguishing between daytime and nighttime attacks. All these issues

may reduce the reliability of results if they are not taken into account $\left(\operatorname{see}^{12,14,22,31,79}\right)$. Nevertheless, as a similar experiment design was used in all experimental sites, the observed differences in attack rates can be considered as estimates of relative differences in potential predation rates. And taking into account the limitations of the technique and our experimental design, our results can only be considered as viable estimates of the potential predation rates on immobile lizards that did no detect the predator's approach, small lizards or in juvenile stages and for diurnal birds as predators.

The dearth of ecological and behavioral studies in semi-arid areas and the peculiarities of these environments raise interesting questions regarding the assemblage dynamics and community processes. Results presented here using a simple and low-cost experiments confirm the strong association of predation risks with local abiotic conditions caused by seasonal changes rather than structural complexity of habitats in a semi-arid caatinga of northeastern Brazil. Thus, our study, suggest consistent guidelines of the relative importance of these processes in determining predation risk in the caatinga domain. To our knowledge, this is the first study done in the domain of the caatinga that provide empirical evidence of the complex process of predation pressure using an experiment based on lizard replicas. It is hoped the current study will stimulate further standardized comparisons of trophic interactions on predation risk in the real world, contributing to a better understanding of these key biological interactions, and thus illuminating our search for their drivers and consequences.

\section{Methods}

Study area. This study was conducted in the Grota do Angico Natural Monument - GAMN $\left(09^{\circ} 39^{\prime}\right.$ S; $37^{\circ} 40^{\prime} \mathrm{W}$ ), a 2.183 ha protected area (mean elevation $100 \mathrm{~m}$ a.s.I.), located on the right margin of the São Francisco River, Sergipe state, northeastern Brazil. The study area lies within the seasonally dry tropical forest in the semi-arid region of Brazil (Fig. 3), known as caatinga which covers approximately 850.000 $\mathrm{Km}^{2}$ (some $10 \%$ of Brazil's land surface), and comprises a large part of northeastern Brazil ${ }^{80}$. The caatinga is also the most impacted and the least studied of all Brazilian biomes, being subjected to great anthropic pressure due, primarily, to agriculture expansion and extensive live-stock farming and wood extraction ${ }^{81}$. This has resulted in a $45.6 \%$ reduction of the original vegetation $\operatorname{cover}^{82}$. The predominant phytophysiognomy at GAMN is classified as deciduous and composed of semi-arid thorny woodland and xerophytic formations growing on shallow and rocky soils ${ }^{83}$. The arboreal-shrub vegetation at GAMN is secondary successional, with a sparse understory and herb layers ${ }^{83}$. The regional climate is arid (BShw classification of Köppen), with high solar radiation (with an accentuated diurnal range, but with means of around $30^{\circ} \mathrm{C}$ during the dry season), low cloud cover, low relative humidity, and rainfall that is both annually low (annual average around $500 \mathrm{~mm}$ ) and irregular within and between years ${ }^{84-86}$. 
Experimental sites. At the GAMN, eight standardized sampling stations were maintained along three sites with different physical structures. For the present study, we performed replica-based predation experiments in 24 stations in these three research sites which are spread along a 5-km-long transect. The general features of these experimental sites are: S1: an area with arboreal-shrubby vegetation, with shallow, clayey, stony soil covered by leaf litter with few apparent rock outcrops, and few bromeliad patches. S2: an area of sparse shrub, on shallow, stony, clayey soil, and with extensive patches of bromeliads scattered throughout the entire area. S3: an alluvial terrace with sandy soil and predominantly herbaceous-shrub vegetation, dominated by Croton campestris (locally known as velame do campo), and scattered large trees.

To test for effects of habitat complexity and seasonality on predation risk, we characterized the physical structure of each station and site in monthly visits of three consecutive days from January 2012 to June 2013; and to determine the impact of seasonality we used operational definitions based on historical averages for precipitation for the area between 2003 and 2013 (source: SEMARH/SE). Months where precipitation exceeded $45 \mathrm{~mm}$ (historical average) were considered part of the rainy season. Values lower than this threshold were assigned to the dry season. Accordingly, the rainy season is from April to August, and the dry season from September to March (Supplementary Fig. S1).

To quantify vegetation complexity, we used a square frame made of $0.5 \times 0.5 \mathrm{~m}$ PVC tube $(42.16 \mathrm{~mm})$, divided into 25 smaller and equal squares $(0.1 \times 0.1 \mathrm{~m}$ each). From the central point at each station, we threw the frame four times in each cardinal direction (N, S, E and W), totaling 32 times per site. At each quadrat frame, the following parameters were measured: percentage area with leaf litter, rock and exposed soil. These types of coverage were assigned to each sub-section $(0.1 \times 0.1 \mathrm{~m})$ of the frame when a given coverage type had $>50 \%$ for that sub-section. Then, these data were converted to an overall cover percentage for the whole quadrat frame. We also measured the number of stems (from the central point of the quadrat frame, a $1 \mathrm{~m}$-long pole was rotated $360^{\circ}$ at $25 \mathrm{~cm}$ above the soil surface, and the number of stems that it touched were counted); distance and trunk diameter of the nearest tree (from the central point of the quadrat frame, and including only arborescent vegetation with diameter at breast height $(\mathrm{DBH}) \geq 5 \mathrm{~cm}$ ); number of fallen logs (within quadrat frame and with $\mathrm{DBH} \geq 10 \mathrm{~cm}$ and length longer than $1 \mathrm{~m}$ ); and area covered by bromeliads within quadrat frame.

Lizard replica construction. We used commercially available flexible plastic replica lizards (Safari Ltd., Miami, Florida, USA) which we coated with non-toxic and odourless modelling clay (Plastalina ${ }^{\circledR}$ - Din Clay Shop, São Paulo, Brazil). We dipped lizard replicas into melted Plastalina modeling clay allowed some of the liquefied clay to run off, and then let the clay on the replicas cool. The clay formed a thin layer without modifying the body form of the replicas, while providing a soft layer retains predator marks ${ }^{17-19}$. We used clay replicas as surrogates for a lizard community. Eleven species of lizards have been documented from the GAMN region with morphological differences in size, color, shape and activity periods ${ }^{87}$. All replicas were standardized in size ( $8 \mathrm{~mm}$ wide, $75 \mathrm{~mm}$ long), color (brown) and shape (Fig. 4). Although the replicas are not similar for all adult lizard species present in the study area (e.g., Ameiva ameiva, Ameivula ocellifera, Tropidurus hispidus and T. semitaeniatus), we used standard lizard 
replicas as a model to address this issue and also to not introduce extra variables into the analyses. There are no species in the GAMN that at the adult stage are smaller, and thus, outside the range of potential predators of the $75 \mathrm{~mm}$ long clay replicas. However, using brow-colored and odourless replicas may have some limitations (see ${ }^{11,12}$ ). On the other hand, Castilla et al. (1999) showed that replicas experienced high attack rates regardless of the contrast between body color. Nevertheless, brow color was considered the best option, both because it represents the most common back color pattern among the lizard species of the region, and because it does not cause great contrasts with the microhabitats where they were placed (soil, rock and trees). Furthermore, attempts to emulate color are far more likely to create problems than provide solutions (see also ${ }^{11,38,88}$ ). The proportions of the head, torso and tail were measured with the aid of a digital caliper (accuracy $0.01 \mathrm{~mm}$ ) and were 1.16, 2.26 and 4.08, respectively.

Experimental design. Replica-based experiments were carried out on seven consecutive days (period in which lizards are exposed to their potential predators, being active or even sleeping), and in both seasons (July - rainy season and November - dry season) during 2013. At each station, we positioned 20 lizard replicas (about 3-5 m spacing), a total of 160 replicas per site (480 replicas per season and 960 in total). All replicas at each experimental site and in both seasons were put in place in a single day. They were positioned to ensure they were all equally conspicuous being placed on surfaces where basking lizards had been observed previously. Replicas were located in places visible from overhead, and in a position that simulated an immobile basking lizard. Replicas were placed in the same orientation (horizontally placed), in three different microhabitats: soil, rock and tree (at a height of 1-2 $\mathrm{m}$ above the ground, and fixed to the trunk with a drop of odourless acrylic glue to prevent being blown away by the wind). These microhabitats were typical of those used by all the lizards native to the study area (e.g., Acratosaura, Ameiva, Ameivula, Brasiliscincus, Tropidurus, Vanzosaura). Inter-site variations meant that the number of replicas in the three microhabitats at each station varied between sites, this lack of standardization is natural, as they represent the microhabitats available to the real lizards in each site, and therefore, has no impact on the results.

Subsequently, all replicas were inspected once a day for evidence of attack. During each census, we recorded the replica circumstances (as intact, attacked or missing). Whenever an attack was scored, the replica in question was removed without replacement, because we consider that a predation event means that an individual is no longer available to predators. On those occasions when replicas were moved by predators from the initial location, a thorough search was made within a five meter radius around the point where the replica was originally placed. Missing replicas were scored as predated and were also not replaced ${ }^{22,25}$. Each attacked replica was inspected with a stereoscopic microscope to reliably identify marks left by predators. Marks made by the potential visually oriented predators (birds, ants, lizards and mammals) are different and distinguishable (Fig. 5). Birds leave V-shaped marks that lack tooth imprints, carnivorous ants leave cut-shaped marks (mandibles), lizards leave U-shaped marks with distinct tooth imprints, and mammals leave incisor or square-shape tooth marks $11,27,33,89$, A.S.F. personal observation; Fig. 5). Cases where marks could not be attributed to a particular class of predator were classified as unknown. In most such cases, the replica had been attacked with such intensity that no specific marks 
could be used to identify the predator positively. We also recorded the replica body region on which the attack occurred (head, torso, tail or limbs). Replicas with marks in multiple regions of the body were classified as a distinct category (all). Due to the complexity and high richness of predator species in the caatinga, we did not evaluate predators by species, but categorized by predator classes (e.g., birds, lizards and mammals), the exception was the ant Dinoponera quadriceps, the only known potential lizard predator ant for the study area.

Statistical analysis. We used a Principal Component Analysis (PCA) to classify experimental sites according to their structural complexity given the analyzed environmental data by visually checking for overlapping sites in the environmental space. We performed a PCA between the three experimental sites using the eight environmental variables measured for all months to test the general structure. Additionally, we performed a PCA for each season (dry and rainy) to assay the environmental differences caused by seasonality. Because the environmental variables had different scales, we used the command "scale $=T R U E$ " in the prcomp function of the vegan $\mathrm{R}$ packae. We also used a multivariate analysis of variance (MANOVA) to test for significant differences between PCA scores. The first two Principal Components (PCs) of the PCA were used as dependent variables, and experimental sites was used as a factor.

We used generalized linear mixed models (GLMMs) with binomial error distribution to quantify differences in attack rates between habitat complexity and season. We used the attack rates (1 - attacked or 0 - not attacked) as a binary response variable (dependent variable), habitat complexity (S1, S2 and S3) and seasons (dry and rainy) as explanatory variables (fixed effects), experimental sites (stations) and microhabitats (soil, rock and tree) as random effects. The absolute frequencies of attacks on replica body parts (head, torso and tail) were compared to the expected frequencies calculated from their relative surfaces, by means of a $x^{2}$ goodness-of-fit test. In the predator class, we only consider birds, because lizards and mammals had less than five attacks on the replicas (four and three attacks, respectively), and although we recorded 14 attacks by the giant ant (Dinoponera quadriceps), ants are not counted as lizard predators ${ }^{11,33,34}$. All statistical analyses were performed with R 3.5 .0 software $^{90}$, and we used $a<0.05$ to assess significance.

\section{Declarations}

\section{Data Availability}

Data will be made available from the Dryad Digital Repository.

\section{Acknowledgments}

Data were obtained with the support of the Secretaria de Estado do Meio Ambiente e dos Recursos Hídricos - SEMARH, Universidade Federal de Sergipe - UFS, and Fundação de Apoio à Pesquisa e a Inovação Tecnológica do Estado de Sergipe (Edital: 04/2011 - Fapitec/SE - CNPq - PPP). A. S. Ferreira received fellowships from CAPES while conducting this study and a fellowship from MCTI/CNPq (proc. 
301293/2021-0, Programa de Capacitação Institucional/PCl) while conducting activities related to this work. We are especially grateful to Manoel Messias Nazaré, known as "Seu Didi" and his entire family for their assistance and hospitality, and Mayane Vieira and Bruna Gomes for helping with the monitoring of lizard replicas in the field. We thank Albertina P. Lima, Diana P. Rojas, Diego A. Ortiz for their constructive comments on the manuscript.

\section{Author contributions}

ASF and RGF conceived the project idea and designed methodology; ASF collected and analysed data and led the writing of the manuscript; ASF and RGF both contributed critically to drafts and approved the final manuscript.

\section{Competing interests}

The corresponding author confirms on behalf of all authors that there have been no involvements that might raise the question of bias in the work reported or in the conclusions, implications, or opinions stated.

\section{ORCID}

Anthony S. Ferreira https://orcid.org/0000-0002-3718-8049 Renato G. Faria https://orcid.org/0000-00034105-3048

\section{References}

1. Pianka, E. R. Niche relations of desert lizards in Ecology and Evolution of Communities, Cody, M. L. \& Diamond, J. M. (Eds). (Harvard University Press, 1975).

2. Castilla, A. M. \& Labra, A. Predation and spatial distribution of the lizard Podarcis hipanica atrata: an experimental approach. Acta Oecol. 19, 107-114 (1998).

3. Cantwell, L. R. \& Forrest, T. G. Response of Anolis sagrei to acoustic calls from predatory and nonpredatory birds. J. Herpetol. 47, 293-298 (2013).

4. Edmund, M. Defense in animals: A survey of antipredator defenses. (Longman Press, 1974).

5. Wilcove, D. Nest predation in forest tracts and the decline of migratory songbirds. Ecology $66,121 \mathrm{I}-\mathrm{I} 214$ (1985).

6. Endler, J. A. Defense against predators in Predator-prey relationships, Feder, M. E. \& Lauder, G. V. (Eds). (The University of Chicago Press, 1986).

7. Constantini, D., Bruner, E., Fanfani, A. \& Dell'Omo, G. Male-biased predation of western green lizards by Eurasian kestrels. Naturwissenschaften 94, 1015-1020, https://doi.org/10.1007/s00114-007-0284-5 
(2007).

8. Barnett, A. A. et al. Run, hide or fight: anti-predation strategies in Endangered red-nosed cuxiú (Chiropotes albinasus, Pitheciidae) in south-eastern Amazonia. Primates 58, 353360, https://doi.org/10.1007/s10329-017-0596-9 (2017).

9. Barnett, A. A. et al. Honest error, precaution or alertness advertisement? Reactions to vertebrate pseudopredators in red-nosed cuxiús (Chiropotes albinasus), a high-canopy neo-tropical primate. Ethology 124, 177-187, https://doi.org/10.1111/eth.12721 (2018).

10. Roslin, T. et al. Higher predation risk for insect prey at low latitudes and elevations. Science 356, 742744, https://doi.org/10.1126/science.aaj1631 (2017).

11. Shepard, D. B. Habitat but not body shape affects predator attack frequency on lizard models in the Brazilian Cerrado. Herpetologica 63, 193-202. https://doi.org/10.1655/00180831(2007)63[193:HBNBSA]2.0.CO;2 (2007).

12. Salvidio, S., Costa, A. \& Romano, A. The use of clay models in amphibian field studies: a short review. Bull. Env. Life Sc. 1, 8, https://doi.org/10.15167/2612-2960/BELS2019.1.1.1048 (2019).

13. Castilla, A. M., Gosá, A., Galán, P. \& Pérez-Mellado, V. Green tails in lizards of the genus Podarcis: do they influence the intensity of predation? Herpetologica 55, 530-537 (1999).

14. Bateman, P. W., Fleming, P. A. \& Wolfe, A. K. A different kind of ecological modelling: the use of clay model organisms to explore predator-prey interactions in vertebrates. J. Zool. 301, 251-262, https://doi.org/10.1111/jzo.12415 (2017).

15. Rössler, D., Pröhl, H. \& Lötters, S. The future of clay model studies. BMC Zool. 3, 6, https://doi.org/1010.1186/s40850-018-0033-6 (2018).

16. Major, R. E. \& Kendal, C. E. The contribution of artificial nest experiments to understanding avian reproductive success: a review of methods and conclusions. Ibis 138, 298-307 (1996).

17. Kuchta, S. R. Experimental support for aposematic coloration in the salamander Ensatina eschscholtzii xanthoptica: implications for mimicry of Pacific newts. Copeia 2005, 267271, https://doi.org/10.1643/CH-04-173R (2005).

18. Kraemer, A. C., Serb, J. M. \& Adams, D. C. Both novelty and conspicuousness influence selection by mammalian predators on the colour pattern of Plethodon cinereus (Urodela: Plethodontidae). Biol. J. Linn. Soc. 118, 889-900, https://doi.org/10.1111/bij.12780 (2016).

19. Salvidio, S., Palumbi, G., Romano, A. \& Costa, A. Safe caves and dangerous forests? Predation risk may contribute to salamander colonization of subterranean habitats. Sci. Nat. 104, 34, https://doi.org/10.1007/s00114-017-1443-y (2017). 
20. Mcelroy, M. T. Teasing apart crypsis and aposematism - evidence that disruptive coloration reduces predation on a noxious toad. Biol. J. Linn. Soc. 17, 285-294, https://doi.org/10.1111/bij.12669 (2016).

21. Nordberg, E. J. \& Schwarzkopf, L. Predation risk is a function of alternative prey availability rather than predator abundance in a tropical savanna woodland ecosystem. Sci. Rep. $\mathbf{9}$,

7718, https://doi.org/10.1038/s41598-019-44159-6 (2019).

22. Costa, A., Coroller, S. \& Salvidio, S. Comparing day and night predation rates on lizard-Like clay models. Herpetol. Conserv. Biol. 15, 198-203 (2020).

23. Nour, N., Matthysen, E. \& Dhondt, A. A. Artificial nest predation and habitat fragmentation: different trends in birds and mammal predators. Ecography 16, 111-116 (1993).

24. Castilla, A. M. Intensive predation of Audouin's Gull nests by the yellow legged gull in the Columbretes islands. Colon Waterbirds 18, 226-230, https://doi.org/10.2307/1521487 (1995).

25. Diego-Rasilla, F. J. Influence of predation pressure on the escape behaviour of Podarcis muralis lizards. Behav. Processes 63, 1-7, https://doi.org/10.1016/S0376-6357(03)00026-3 (2003).

26. Stuart-fox, D. M., Moussalli, A., Marshall, N. J. \& Owens, I. P. F. Conspicuous males suffer higher predation risk: Visual modeling and experimental evidence from lizards. Anim. Behav. 66, 541550, https://doi.org/10.1006/anbe.2003.2235 (2003).

27. Husak, J. F., Macedonia, J. M., Fox, S. F. \& Sauceda, R. C. Predation cost of conspicuous male coloration in collared lizards (Crotaphytus collaris): an experimental test using clay-covered model lizards. Ethology 112, 572-580. https://doi.org/10.1111/j.1439-0310.2005.01189.x (2006).

28. Keehn, J. E. \& Feldman, C.R. Predator attack rates and anti-predator behavior of Side-blotched Lizards (Uta stransbuiana) at Southern California Wind Farms, USA. Herpetol. Conserv. Biol. 13, 194-204 (2018).

29. Hansen, N. A., Sato, C. F., Michael, D. L., Lindenmayer, D. B. \& Driscoll, D. A. Predation risk for reptiles is highest at remnant edges in agricultural landscapes. J. Appl. Ecol. 56, 31-

43, https://doi.org/10.1111/1365-2664.13269 (2019).

30. Hegna, R. H., Saporito, R. A., Gerow, K. G. \& Donnelly, M. A. Contrasting colours in an aposematic frog do not affect predation. Ann. Zool. 48, 29-38, https://doi.org/10.5735/086.048.0103 (2011).

31. Paluh, D. J., Hantak, M. M. \& Saporito, R. A. A test of aposematism in the dendrobatid poison frog Oophaga pumilio: the importance of movement in clay model experiments. J. Herpetol. 48, 249254, https://doi.org/10.1670/13-027 (2014).

32. Rojas, D. P., Stow, A., Amézquita, A., Simões, P. I. \& Lima, A. P. No predatory bias with respect to colour familiarity for the aposematic Adelphobates galactonotus (Anura: Dendrobatidae). Behaviour 152, 1637165, https://doi.org/10.1163/1568539X-00003297 (2015). 
33. Brodie, III. E. D. Differential avoidance of coral snake banded patterns by free-ranging avian predators in Costa Rica. Evolution 47, 227-235, https://doi.org/10.1111/j.1558-5646.1993.tb01212.x (1993).

34. Brodie, III. E. D. \& Janzen, F. J. Experimental studies of coral snake mimicry: Generalized avoidance of ringed snake patterns by free-ranging avian predators. Funct. Ecol. 9, 186190, https://doi.org/10.2307/2390563 (1995).

35. Pfennig, D. W., Harper, Jr. G. R., Brumo, A. F., Harcombe, W. R. \& Pfennig, K. S. Population differences in predation on Batesian mimics in allopatry with their model: Selection against mimics is strongest when they are common. Behav. Ecol. Sociobiol. 61, 505-511, https://doi.org/10.1007/s00265-006-0278-x (2006).

36. Martín, J. \& López, P. An experimental test of the costs of antipredatory refuge use in the wall lizard, Podarcis muralis. Oikos 84, 499-505 (1999).

37. Amo, L., López, P. \& Martín, J. Refuge use: A conflict between avoiding predation and losing mass in lizards. Physiol. Behav. 90, 334-343, https://doi.org/10.1016/j.physbeh.2006.09.035 (2007).

38. Endler, J. A. Interactions between predators and prey in Behavioural Ecology: An Evolutionary Approach, Krebs, J. R. \& Davies, N. B., (Eds). (Blackwell, Oxford, 1991).

39. Denno, R. F., Finke, D. L. \& Langellotto, G. A. Direct and indirect effects of vegetation structure and habitat complexity on predator-prey and predator-predator interactions in Ecology of Predator-prey Interactions, Barbosa, P. \& Castellanos, I. (Eds). (Oxford University Press, 2005).

40. Ruxton, G. D., Sherratt, T. N. \& Speed, M. P. Avoiding Attack: The evolutionary ecology of crypsis, warning signals, and mimicry. (Oxford University Press, 2004).

41. Sih, A. To hide or not to hide? Refuge use in a fluctuating environment. Trends Ecol. Evol. 12, 375-6 (1997).

42. Martín, J., López, P. \& Cooper, Jr. W. E. When to come out from a refuge: balancing predation risk and foraging opportunities in an alpine lizard. Ethology 109, 77-87, https://doi.org/10.1046/j.14390310.2003.00855.x (2003).

43. Bulova, S. J. Ecological correlates of population and individual variation in antipredator behaviour of two species of desert lizards. Copeia 4, 980-992, https://doi.org/10.2307/144 6721 (1994).

44. Vanhooydonck, B. \& Van Damme, R. Relationships between locomotor performance, microhabitat use and antipredator behaviour in lacertid lizards. Func. Ecol. 17, 160-169, https://doi.org/10.1046/j.13652435.2003.00716.x (2003).

45. Vervust, B., Grbac, I. L. \& Van Damme, R. Differences in morphology, performance and behavior between recently diverged populations of Podarcis sicula mirror differences in predation pressure. Oikos 
116, 1343-1352, https://doi.org/10.1111/j.2007.0030-1299.159 89.x (2007).

46. Smith, G. R. \& Ballinger, R. E. The ecological consequences of habitat and microhabitat use in lizards: a review. Contemp. Herpetol. 3, 1-13, https://doi.org/10.1002/3527600213.ch1 (2001).

47. Wüster, W. et al. Do aposematism and Batesian mimicry require bright colours? A test, using European viper markings. Proc. Roy. Soc. London 271, 2495-2499, https://doi.org/10.1098/rspb.2004.2894 (2004).

48. Worthington-Hill, O. \& Gill, A. Effects of large-scale heathland management on thermal regimes and predation on adders Vipera berus. Anim. Conserv. 22, 481-492, https://doi.org/10.1111/acv.12489 (2019).

49. Chiang, J. C. H. \& Koutavas, A. Tropical flip-flop connection. Nature 432, 684-685, https://doi.org/10.1038/432684a (2004).

50. Carmo, R. F. R., Amorim, H. P. \& Vasconcelos, S. D. Scorpion diversity in two types of seasonally dry tropical forest in the semi-arid region of Northeastern Brazil. Biota Neotropica 13, 340344, https://doi.org/10.1590/S1676-06032013000200037 (2013).

51. Warrick, G. D., Kato, T. T. \& Rose, B. R. Microhabitat use and home range characteristics of Blunt-nosed leopard lizards. J. Herpetol. 32, 183-191 (1998).

52. Constantini, D. \& Dell'Omo, G. Sex-Specific predation on two lizard species by kestrels. Russ. J. Ecol. 41, 99-101, https://doi.org/10.1134/S1067413610010182 (2010).

53. Poulin, B. et al. Avian predation upon lizards and frogs in a neotropical forest understory. J. Trop. Ecol. 17, 21-40, https://doi.org/10.1017/S026646740100102X (2001).

54. Araújo, C. S., Candido, D. M., Araújo, H. F. P., Dias, S. C. \& Vasconcellos, A. Seasonal variations in scorpion activities (Arachnida: Scorpiones) in an area of Caatinga vegetation in Northeastern Brazil. Zoologia 27, 372-376, https://doi.org/10.1590/S1984-46702010000300008 (2010).

55. Vasconcellos, A. et al. Seasonality of insects in the semi-arid Caatinga of northeastern Brazil. Rev. Bras. Entomol. 54, 471-476, https://doi.org/10.1590/S0085-56262010000300019 (2010).

56. Schall, J. J. \& Pianka, E. R. Evolution of escape behavior diversity. Am. Nat. 115, 551-566 (1980).

57. Martín, J. \& López, P. Influence of habitat structure on the escape tactics of the lizard Psammodromus algirus. Can. J. Zool. 73, 129-132 (1995).

58. Rocha, C. F. D. \& Bergallo, H. G. Intercommunity variation in the distribution of abundance of dominant lizard species in restinga habitats. Ciencia e Cultura 49, 269-274 (1997).

59. Van-Sluys, M. Growth and body condition of the saxicolous lizard Tropidurus itambere in southeastern Brazil. J. Herpetol. 32, 359-365 (1998). 
60. Liebezeit, J. R. \& Zack, S. Point counts underestimate the importance of arctic foxes as avian nest predators: evidence from remote video cameras in arctic Alaskan oil fields. Arctic 61, 153161, https://doi.org/10.14430/arctic32 (2008).

61. DeGregorio, B. A., Weatherhead, P. J. \& Sperry, J. H. Power lines, roads, and avian nest survival: Effects on predator identity and predation intensity. Ecol. Evol. 4, 1589-1600, https://doi.org/10.1002/ece3.1049 (2014).

62. Huey, R. B. \& Pianka, E. R. Ecological consequences of foraging mode. Ecology 62, 991-999 (1981).

63. Greene, H. W. Antipredator mechanisms in reptiles in Biology of Reptilian, Gans, C. \& Huey, R. B. (Eds.). (New York, USA, 1998).

64. Martín, J. \& López, P. Amphibians and reptiles as prey of birds in southwestern Europe. Smit. Herpetol. Inform. Serv. 82, 1-43 (1990).

65. Steffen, J. E. Perch-height specific predation on tropical lizard clay models: implications for habitat selection in mainland neotropical lizards. Rev. Biol. Trop. 57, 859864, https://doi.org/10.15517/rbt.v57i3.5498 (2009).

66. Dunham, A.E., Grant, B.W. \& Overall, K. L. Interfaces between biophysical and physiological ecology and the population ecology of terrestrial vertebrate ectotherms. Physiol. Zool. 62, 335-355 (1989).

67. Ruiz-Esparza, J. et al. Birds of the Grota do Angico Natural Monument in the semi-arid Caatinga scrublands of northeastern Brazil. Biota Neotropica 11, 1-8, https://doi.org/10.1590/S1676-06032011 000200027 (2011).

68. Lima, C. P., Santos, S. S. \& Lima, R. C. Levantamento e Anilhamento da Ornitofauna na Pátria da Arara-Azul-de-Lear (Anodorhynchus leari, Bonaparte, 1856): um complemento ao Levantamento realizado por Sick, H., Gonzaga, L. P. e Teixeira, D. M., 1987. Atual. Ornitol. 112, 11-22 (2003).

69. Roos, A. L. et al. Avifauna da região do Lago de Sobradinho: composição, riqueza e biologia. Ornithologia 1, 135-160 (2006).

70. Farias, G. B., Pereira, G. P. \& Burgos, K. Q. Aves da Floresta Nacional de Negreiros (Serrita, Pernambuco). Atual. Ornitol. 157, 41-46 (2010).

71. Sousa, P. A. G. \& Freire, E. M. X. Coleodactylus natalensis (NCN). Predation. Herpetol. Rev. 41, 218 (2010).

72. Ribeiro, L. B., Gogliath, M. \& Freire, E. M. X. Hemidactylus brasilianus (Amaral's Brazilian Gecko) and Cnemidophorus ocellifer (Spix`s Whiptail). Predation. Herpetol. Bull. 117, 31-32 (2011). 
73. De-Carvalho, C. B. et al. Gymnodactylus geckoides (Naked-Toed Gecko): Predation. Herpetol. Bull. 121, 41-43 (2012).

74. McCormick, S. \& Polis, G. A. Arthropods that prey on vertebrates. Biol. Rev. 57, 29-58 (1982).

75. Rocha, C. F. D. \& Vrcibradic, D. Reptiles as predators of vertebrates and as preys in a restinga habitat of southeastern Brazil. Ciencia e Cultura 50, 364-368 (1998).

76. Armas, L. F. Frogs and lizards as prey of some Greater Antillean arachnids. Rev. Iberica Aracnol. 3, 87$88(2000)$.

77. Schatz, B., Suzzoni, J. P., Corbara, B. \& Dejean, A. Selection and capture of prey in the African ponerine ant Plectroctena minor (Hymenoptera: formicidae). Acta Oecol. 22, 55-60, https://doi.org/10.1016/S1146609X(00)01100-0 (2001).

78. Nordberg, E. J., Edwards, L. \& Schwarzkopf, L. Terrestrial invertebrates: an underestimated predator guild for small vertebrate groups. Food Webs 15, e00080 (2018).

79. Seifert, C. L., Schulze, C. H., Dreschke, T. C. T., Frötscher, H. \& Fiedler, K. Day vs. night predation on artificial caterpillars in primary rainforest habitats - an experimental approach. Entomol. Exp. Appl. 158, 54-59, https://doi.org/10.1111/eea.12379 (2016).

80. Andrade, L. A., Pereira, I. M., Leite, U. T. \& Barbosa, M. R. V. Análise da cobertura de duas fitofisionomias de Caatinga, com diferentes históricos de uso, no município de São João do Cariri, estado da Paraíba. Cerne 11, 253-262 (2005).

81. Castelletti, C. H. M., Silva, J. M. C., Tabarelli, M. \& Santos, A. M. M. Quanto ainda resta da Caatinga? Uma estimative preliminar in Biodiversidade da Caatinga: áreas e ações prioritárias para a conservação, Silva, J. M. C., Tabarelli, M., Fonseca, M. T. \& Lins, L. V. (Eds.). (Ministério do Meio Ambiente Publishing, 2004).

82. Albuquerque, U. P. et al. Caatinga revisited: ecology and conservation of an important seasonal dry forest. Sci. World J. 2012, 1-18, https://doi.org/10.1100/2012/205182 (2012).

83. Da Silva, A. C. C., Prata, A. P. N. \& Mello, A. A. Flowering plants of the Grota do Angico Natural Monument, Caatinga of Sergipe, Brazil. Check List 9, 733-739 (2013).

84. Nimer, E. Climatologia da Região Nordeste do Brasil: Introdução à Climatologia Dinâmica. Rev. Bras. Geog. 34, 3-51 (1972).

85. Santos, A. F. \& Andrade, J. A. O quadro natural: caracterização e delimitação do semi-árido sergipano. Sergipe. Brazil. (CNPq/UFS, 1992). 
86. SEMARH - Secretaria de Estado do Meio Ambiente e dos Recursos Hídricos. Plano de Manejo do Monumento Natural Grota do Angico. Sergipe, Brazil. (Secretaria de Estado do Meio Ambiente e dos Recursos Hídricos, 2011)

87. Ferreira, A. S., Silva, A. O., Conceição, B. M. \& Faria, R. G. The diet of six species of lizards in an area of Caatiga, Brazil. Herpetol. J. 27, 151-160 (2017).

88. Bennett, A. T. D., Cuthill, I. C. \& Norris, K. J. Sexual selection and the mismeasure of color. Am. Nat. 144, 848-860 (1994).

89. Niskanen, M. \& Mappes, J. Significance of the dorsal zigzag pattern of Vipera latastei gaditana against avian predators. J. Anim. Ecol. 74, 1091-1101. https://doi.org/10.1111/j.1365-2656.2005.01008.x (2005).

90. R Core Team. R: A language and environment for statistical computing (2020).

\section{Tables}

Due to technical limitations, table 1 is only available as a download in the Supplemental Files section.

\section{Figures}





\section{Figure 1}

Overall characterization of landscape change due to seasonality at the Monumento Nat-ural Grota do Angico (MNGA), Sergipe, Brazil. a Experimental site during the rainy season and $b$ Same experimental site during the dry season. 

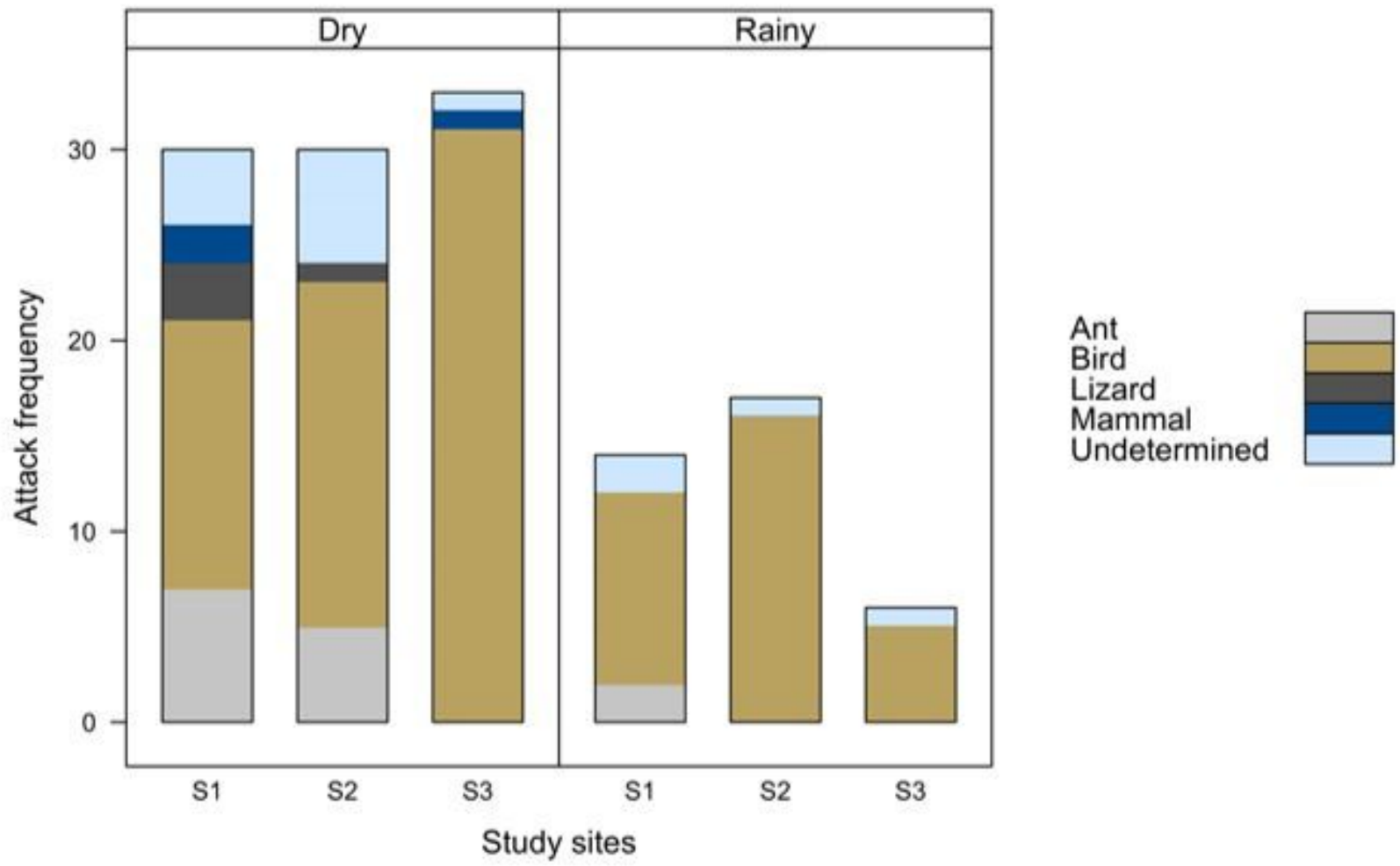

\section{Figure 2}

Artificial lizard replicas $(8 \times 75 \mathrm{~mm})$ used in the field predation experiments. a, b Origi-nal replicas made of flexible plastic. c, d Replicas manually covered with brow-colored non-toxic modelling clay (plastiline). 

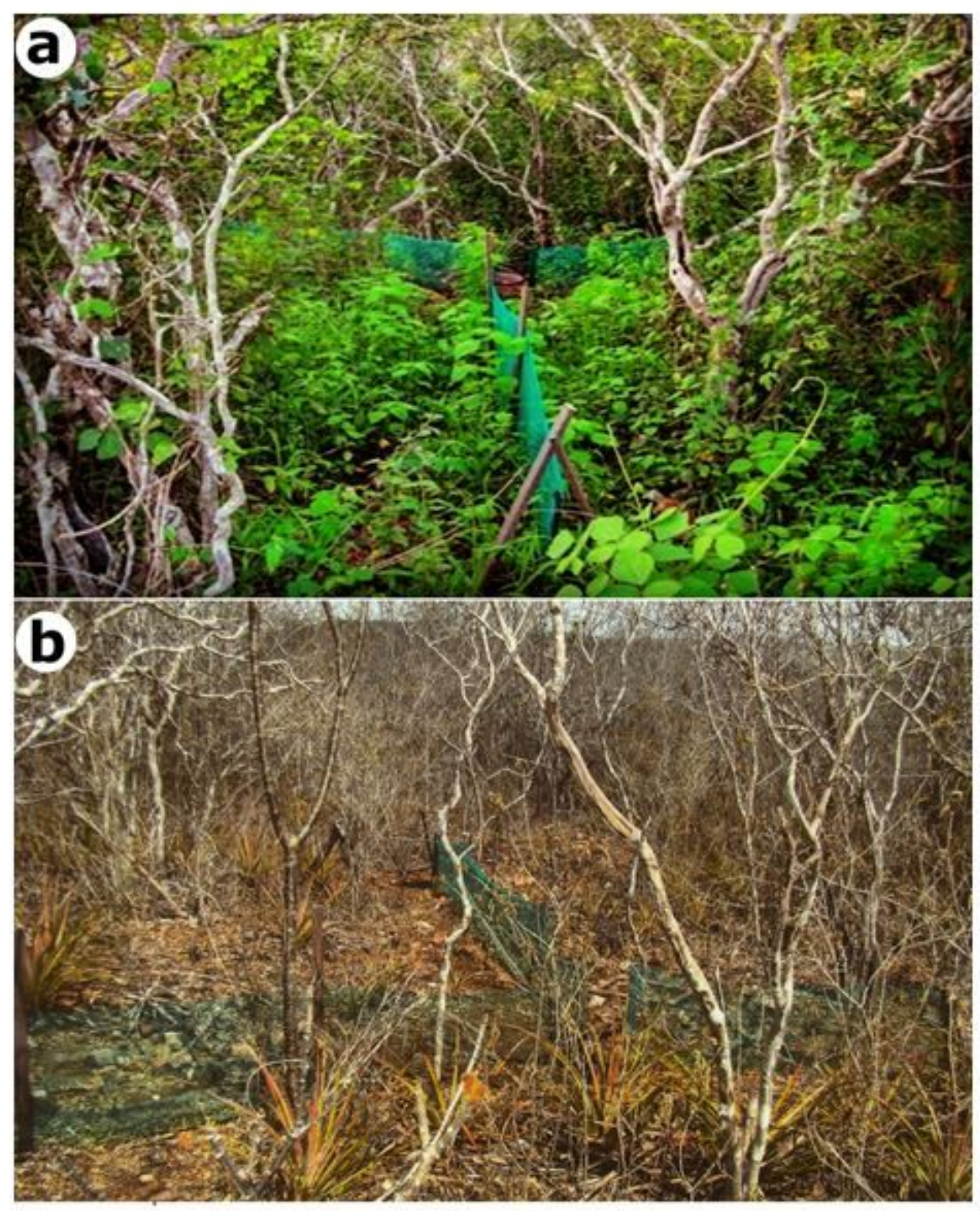

Figure 3

Predator bite marks on lizard replicas coated with modelling clay (plastiline) from field predation experiments. a Bird mark. b Mark from giant ant D. quadriceps. c Lizard mark. d Mark by an omnivorous/carnivorous mammal. 

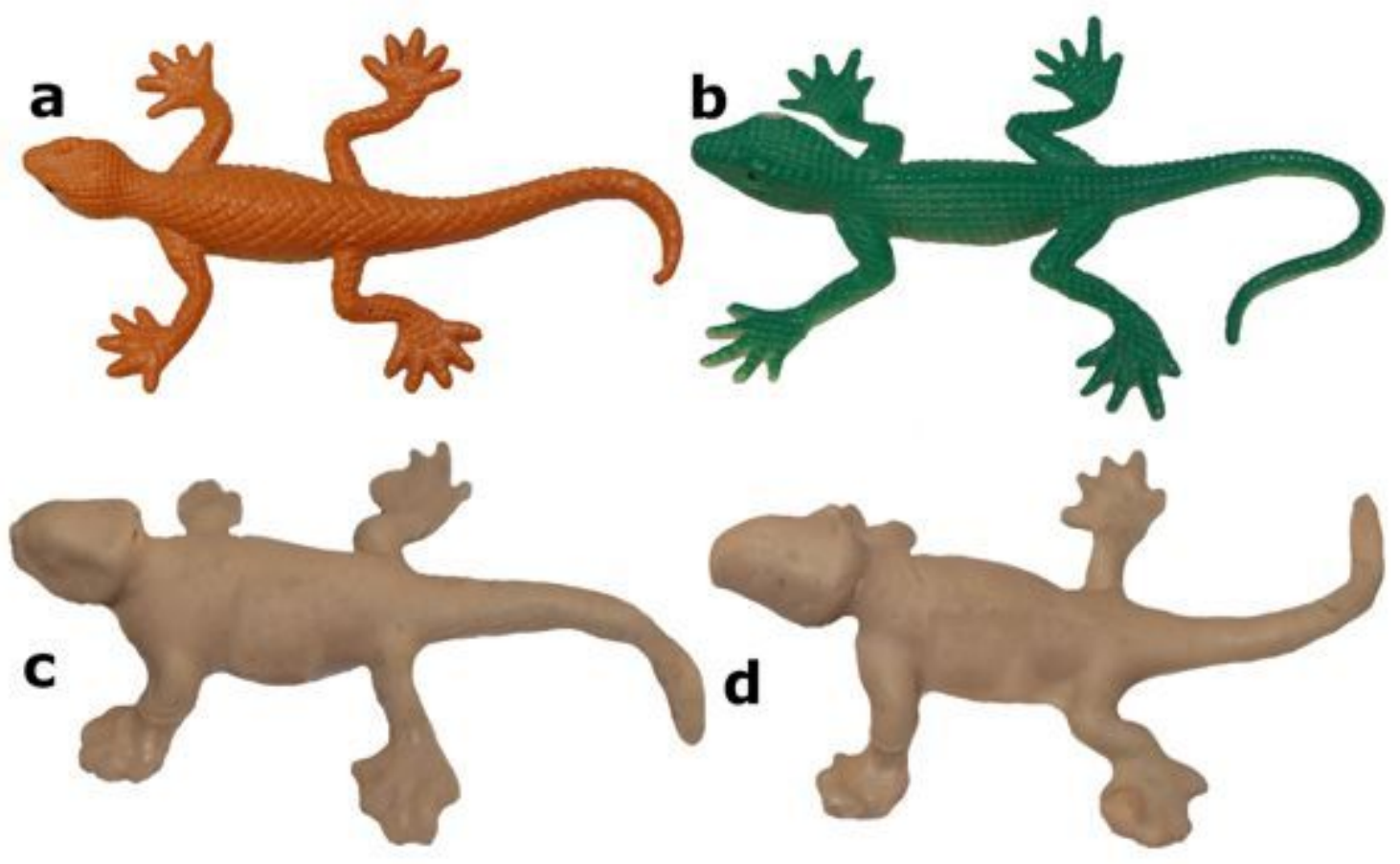

Figure 4

Multivariate environmental space at MNGA. Principal Component Analysis for the eight environmental variables measured at each sampling site (S1, S2 and S3) for 18 consecu-tive months. a General structure (all 18 months). b Dry season only. c Rainy season on-ly. 

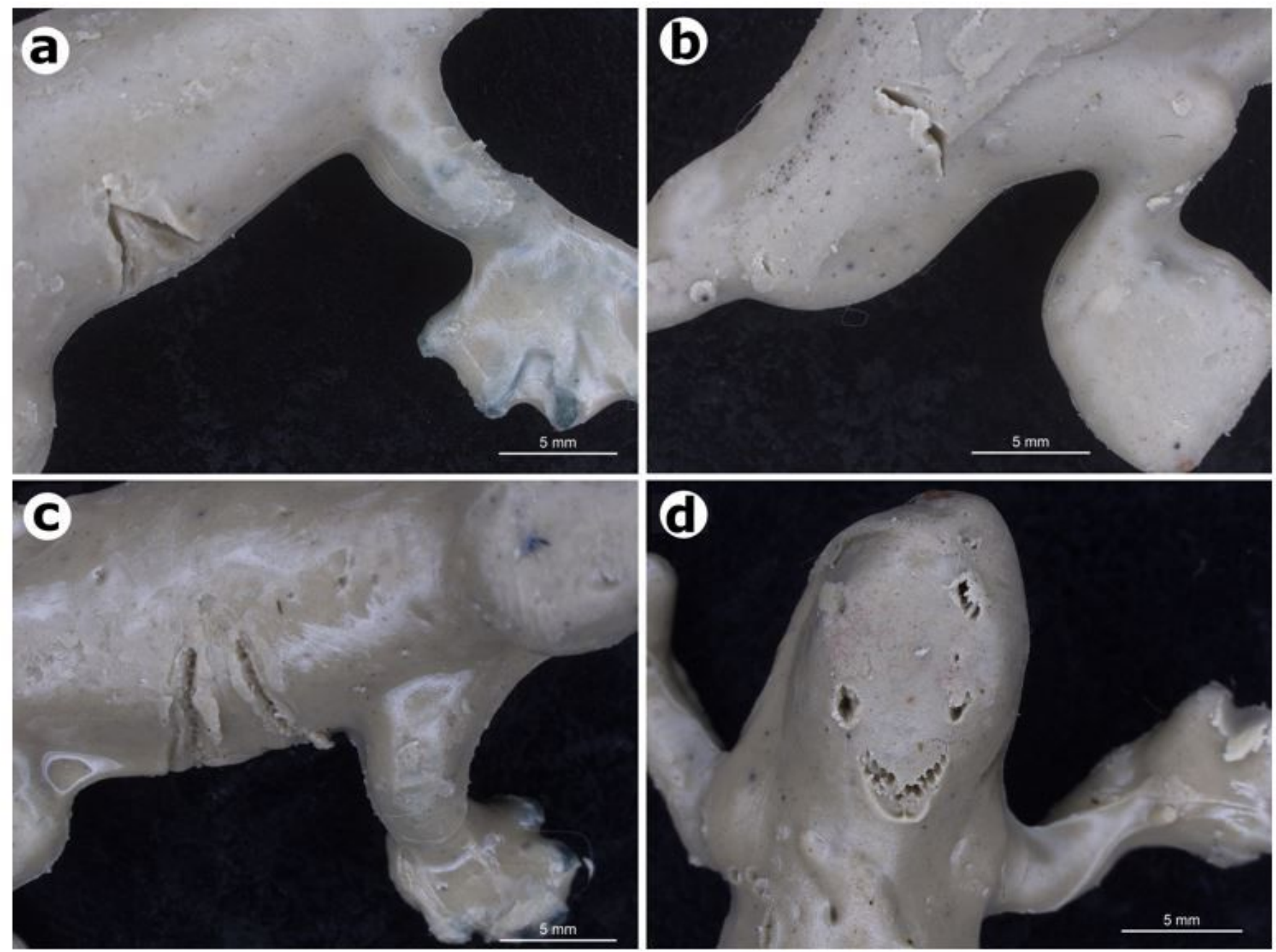

\section{Figure 5}

Frequency of attack by the different categories of predators on the artificial lizard repli-cas arranged by season (dry and rainy) for the three sample sites.

\section{Supplementary Files}

This is a list of supplementary files associated with this preprint. Click to download.

- Supplementaryinformation.pdf

- Table1.docx 